\title{
Comparison of histological changes of sensory neurons of Dorsal Root Ganglion of spinal nerve in different age groups in rabbits Ban Ismail Sddiq ${ }^{1}$, Ali Ghanim Al-Okaili ${ }^{2}$ and Intisar Jasim $^{3}$ \\ ${ }^{1}$ Department of Basic Science, ${ }^{2}$ Department of Oral Surgery, ${ }^{3}$ Department of Oral Diagnosis, College of Dentistry, Tikrit University, Iraq. \\ E-mail: ali.okaili@gmail.com \\ Accepted: 18/3/2015 \\ Summary
}

The aim of the study is to compare the histological changes that occur in the sensory neurons of dorsal root ganglion at L6 and L7 levels of the spinal nerve in different age groups in rabbits. Fifteen rabbits were divided into three groups of equal number according to their age (weaning, maturation and adult). Dorsal root ganglion of spinal nerve at L6 and L7 levels were removed and examined histologically under light microscope. Comparison were made in diameters of neurons and their numbers in different age. The results showed a significant $(\mathrm{P}<0.05)$ decrease in the number of sensory neurons and a significant $(\mathrm{P}<0.05)$ increase in their diameters with advancing age. In conclusion, the structures of sensory neurons are altering by the age factors in which morphology, number, and color of neurons change also.

Keywords: Sensory neurons, Dorsal Root Ganglion, Spinal root, Rabbits.

\section{Introduction}

The peripheral nervous system is involved in the adaptation processes, since by its means they can gather sufficient external information to correlate the environmental changes and their physiological processes (1). The sensory neurons of the Dorsal Root Ganglia (DRGs) provide information about mechanical, thermal, chemical, and noxious external and internal stimuli (2). Dorsal root ganglion neurons, developing as bipolar neurons from the neural crest, are known to have two very similar processes. Both the central and peripheral processes have structural characteristics of axons. The axons of the spinal sensory neurons bifurcate in the DRG, sending one branch in the dorsal root centrally toward the spinal cord and the other in the spinal nerve toward the peripheral tissues (3). Other authors (4) clarified that aging deeply influences several morphological and functional features of the peripheral nervous system. Morphologic studies have reported a loss of myelinated and unmyelinated nerve fibers in elderly subjects, and several abnormalities involving myelinated fibers, such as demyelination, remyelination and myelin balloon figures. Aging also affects functional and electrophysiologic properties of the peripheral nervous system including a decline in nerve conduction velocity, muscle strength, sensory discrimination, and autonomic responses. Concerning the neuronal changes during age (5) on the red nucleus of the mouse brain, the neurons were examined at $6,22,25,28$ and 31 months of age using quantitative histological techniques. Three types of neurons, large, medium and small, were identified on grounds of size and structural characteristics. The number of large neurons remained constant from 6 to 25 months of age before declining from $385+/-$ 24 at 25 months to $126+/-12$ at 31 months. The number of medium neurons remained constant from 6 to 31 months of age with an overall mean of 1139. The number of small neurons showed a slight decline at 31 months of age. The nuclear diameter of large neurons increased from 14.7 microns at 25 months to 15.6 microns at 28 months and this increase in diameter was statistically significant. The nuclear diameter of neither medium mean (12.0 microns) nor small neurons mean (9.6 microns) varied significantly with age

Most researchers study the histomorphic changes of sensory and motor neurons of brain in different age groups and in different animals specially the rodents. Little information were known about the histological changes occurs in the sensory neurons of DRG of spinal cord during life. The present study designated to evaluate the morphological and morphometric changes occur in the sensory neurons of DRG of spinal cord at L6 and L7 levels in three different age groups in Rabbits. 


\section{Materials and Methods}

Fifteen rabbits were used in this study. Animals were divided into three equal groups (5/each) according to their ages: Weaning group [W]: Their ages range between $1-2.5$ months (6). Maturation group [M]: Their ages range between 5-8 months (7) and adult group [A]: Their ages range between 12-18 months (8). Samples were taken from animals. The pedicles of the lower 3 lumbar vertebrae and upper 2 sacral were dissected. The bodies of vertebral column were removed to expose the underlying spinal cord with their associated ganglia (9). Removal of lumbar segment of spinal cord with their associated ganglia from its place in the vertebral canal was manipulated by separating it from the remains part of spinal cord. Preparation of slides for light microscopy: The lumbar segment was removed as one part (Fig. 1) then immersed in $10 \%$ formalin for $24 \mathrm{hs}$, dehydrated in graded alcohols, cleared in xylene, and finally embedded in paraffin wax (10). After removing the tissue from paraffin path and before blocking, DRG was separated from spinal cord at L6 and L7 levels. The procedure was made under vision of surgical loupe (11). According to (12) after blocking, sections were made using rotary microtome. The number of sensory neurons in the spinal cord were counted in 10 microscopically field at objective lens (40X) in both right and left side. The diameter of 20 sensory neurons were measured also at objective lens (40X) multiplied by factor 2.5 (the distance between two adjacent line in the objective lens ruler was equal to $2.5 \mu \mathrm{m}$ ) in both right and left sides. Morphometric data were taken only from those neuronal somas that showed a delineated shape and a distinguishable nucleus (13).

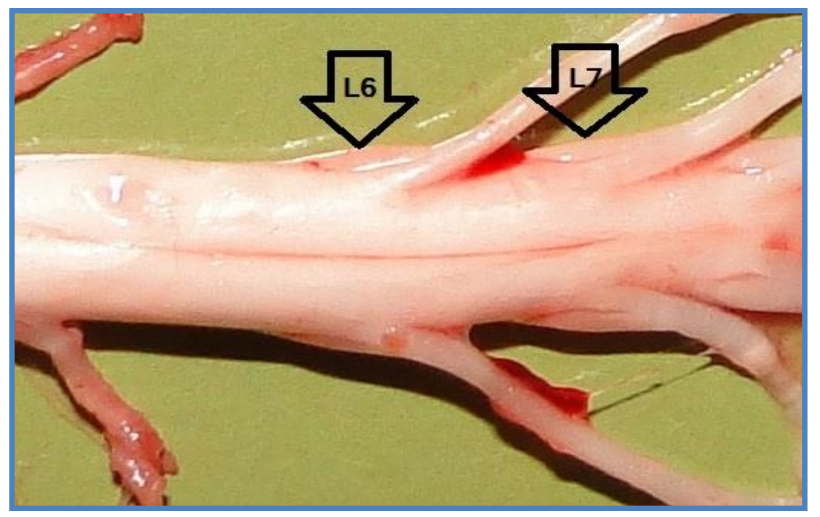

Figure, 1: Lumber segments of rabbit spinal cord with their associated dorsal root ganglia L6 and L7.
Comparison was made among the three age groups and evaluated statistically. The statistical analysis of the experiment results was performed using the general linear model within a ready statistical program (SAS) and Duncan test was performed to determine significant differences between averages at a probability level $(\mathrm{P}<0.05)(14)$.

\section{Results and Discussion}

Aging is the accumulation of changes over time (15). In the present study the influence of age on the morphology, number and diameter of sensory neurons in the dorsal root ganglion of spinal nerve at L6 and L7 levels were compared among different age groups. Sensory neurons were darkly stained with $(\mathrm{H}$ and E) in the weaning group compared with both maturation and adult groups. This result was in agreement with (16) who explained the differences in the color of cytoplasm to the different maturing time of sensory neurons among different ages. It was difficult to recognize Nissl granules in the body of nerve cell of weaning group, while in the maturation and in the adult groups the staining of neurons were normal and Nissl granules appeared clear especially in the adult group. Although, most neurons have round contour, some neurons in the weaning group have oval or elongated appearance, which is characteristic of immature neurons (17 and 18), (Fig. 2-5). Two types of sensory neurons could be recognized clearly in the adult group. The first one large pale in color and the other small dark in color (Fig. 6).

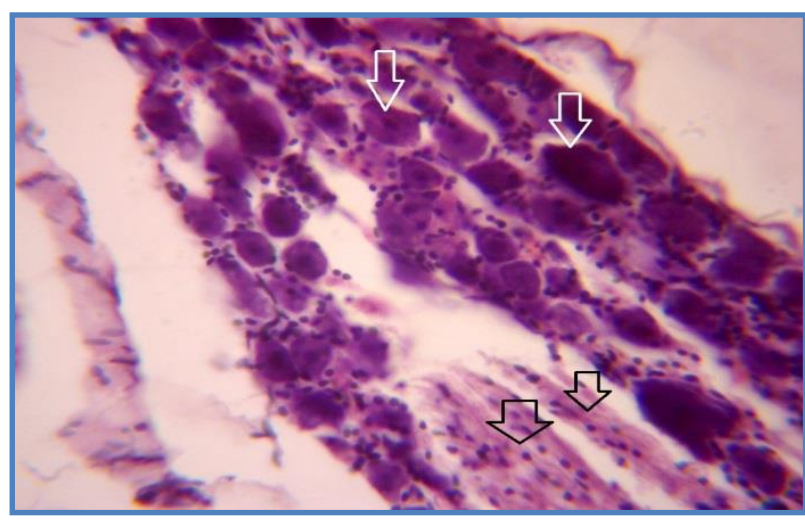

Figure, 2: Weaning group, L6. Sensory neurons small, darkly stained and oval in shape (white arrows). Bundles of nerve fibers (black arrows) $40 X . H$ and $\mathrm{E}$. 


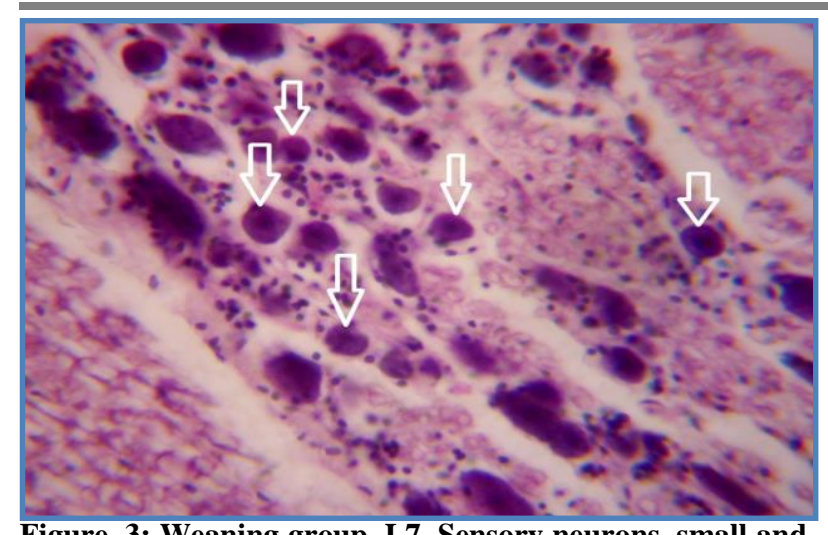

Figure, 3: Weaning group, L7. Sensory neurons, small and darkly stained (arrows) 40X.H and E.

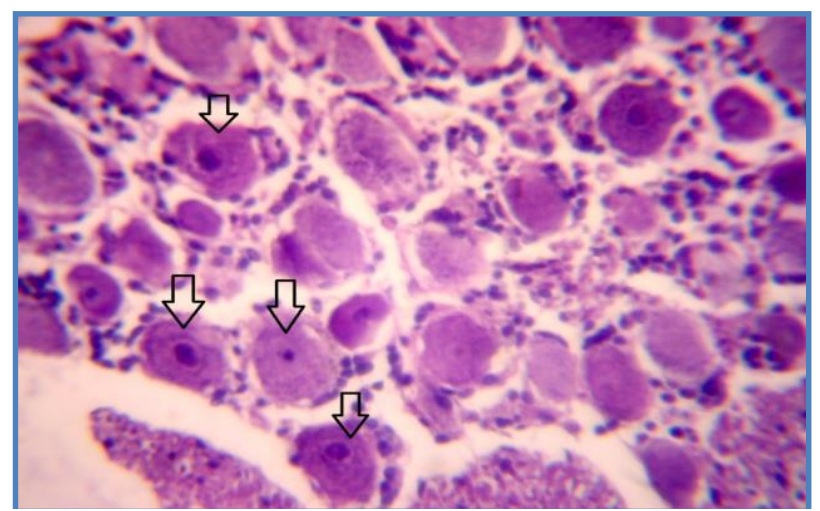

Figure, 4: Maturation group, sensory neurons normal staining and normal size (arrows). 40X, $\mathrm{H}$ and $\mathrm{E}$.

Researchers (19) revealed that, in many aspects the DRG neuronal population is heterogeneous, which permits classifying them into subpopulations and eventually, subpopulations according to their morphology, biochemistry and physiology (membrane properties, peripheral and central connections, among others), which makes each subpopulation behave in a different manner when facing internal and external stimuli. The morphological classification is essentially based on the size of the soma in two neurons types; neurons type A (large and light) and type B (small and dark).

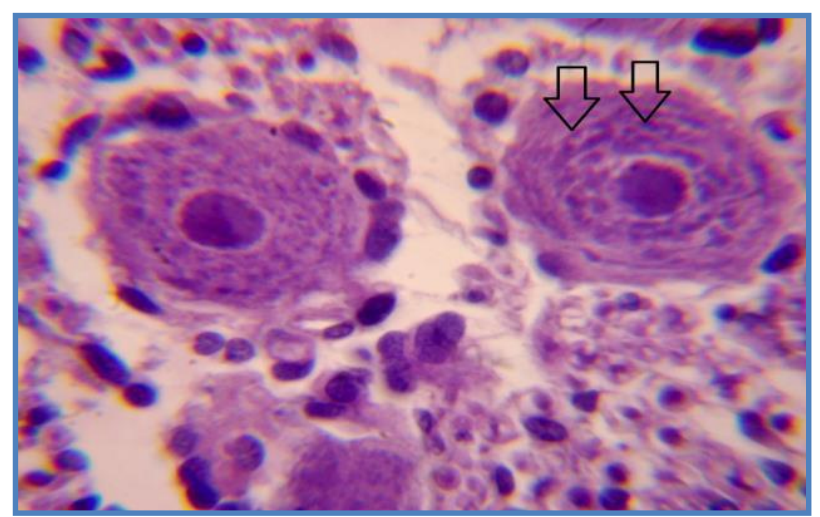

Figure, 5: Adult group sensory neurons, normal staining and Nissl granules appeared very clear (arrows). 100X. H and $E$.

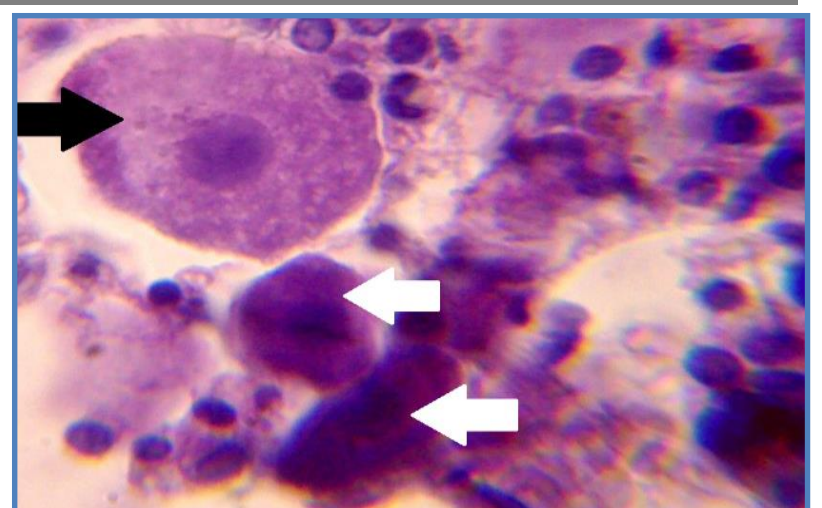

Figure, 6: Adult group sensory neurons, large size neuron (black arrow), small size neurons (white arrows). 100X. H and $\mathbf{E}$.

The number of sensory neurons of DRG at L6 segment level was 81.33 and 80.45 in the right and left sides respectively in the weaning group and 76.02 in the right and 75.37 in the left side in the maturation group and was reduced to 68.44 and 68.44 in the right and left side respectively in the adult group (Table, 1).

Table, 1: Number of sensory neurons at L6 level of rabbit's spinal cord.

\begin{tabular}{|c|c|c|c|c|}
\hline \multirow[t]{2}{*}{ Side } & \multicolumn{3}{|c|}{$\begin{array}{c}\text { Cells Number per microscopical field at } \\
\text { objective lens }(40 \mathrm{X}) \\
(\text { Mean } \pm \text { SE) }\end{array}$} & $\mathbf{P}<0$ \\
\hline & $\mathbf{W}$ & $\mathbf{M}$ & $\mathbf{A}$ & \\
\hline Righ & $81.33 \pm 2.74$ & $76.02 \pm 2.77$ & $68.44 \pm 2.15$ & $*$ \\
\hline Left & $80.45 \pm 2.28$ & $75.37 \pm 2.51$ & $67.61 \pm 2.20$ & $*$ \\
\hline
\end{tabular}

Table (2) showed that the number of sensory neurons in the DRG at L7 segment was 82.33 and 81.62 in the right and left sides respectively in the weaning group and it 77.23 and 77.74 , respectively in maturation group and 73.31 in the right side and 73.86 in the left side in adult group. The results showed that the number of sensory neurons was significantly $\quad(\mathrm{P}<0.05) \quad$ decreased with advancing age in both L6 and L7 segments of spinal cord. Concerning the diameter of sensory neurons, (Table, 3) shows and compares the mean values of the three groups at L6 segment level, which was $24.64 \mu \mathrm{m}$ in the right side and $25.20 \mu \mathrm{m}$ in the left side in case of weaning group and 27.19 and 28.71 $\mu \mathrm{m}$ of the right and left sides respectively in the maturation group. In the adult group the values were 30.89 and $31.24 \mu \mathrm{m}$ of right and left sides respectively. 
Table, 2: Number of sensory neurons at L7 level of rabbit's spinal cord.

\begin{tabular}{|c|c|c|c|c|c|c|}
\hline \multirow[t]{2}{*}{ Side } & \multicolumn{5}{|c|}{$\begin{array}{c}\text { Cells Number per microscopical field at } \\
\text { objective lens }[40 \mathrm{X}] \\
(\mathrm{Mean} \pm \mathrm{SE})\end{array}$} & \multirow[t]{2}{*}{$\mathrm{P}<0.05$} \\
\hline & W & $\mathbf{N}$ & I & 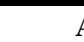 & d & \\
\hline Right & $82.33 \pm 2.11$ & 77.23 & \pm 2.86 & 73.31 & \pm 2.60 & $*$ \\
\hline Left & $81.62 \pm 2.19$ & 77.74 & \pm 2.81 & 73.86 & \pm 2.20 & $*$ \\
\hline
\end{tabular}

Table, 3: Number of sensory neurons diameter ( $\mu \mathrm{m})$ at level L6 segment of rabbits spinal cord.

\begin{tabular}{|c|c|c|c|c|c|c|c|}
\hline \multirow[t]{2}{*}{ Side } & \multicolumn{6}{|c|}{$\begin{array}{l}\text { Cell Diameter } \mu \mathrm{m} \\
(\text { Mean } \pm \mathrm{SE})\end{array}$} & \multirow[t]{2}{*}{$P<0.05$} \\
\hline & & $V$ & $\mathbf{N}$ & & 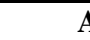 & & \\
\hline Right & 24.64 & \pm 1.54 & 27.19 & \pm 1.14 & 30.89 & \pm 1.67 & $*$ \\
\hline Left & 25.20 & \pm 1.08 & 28.71 & \pm 1.28 & 31.24 & \pm 1.61 & $*$ \\
\hline
\end{tabular}

At the level of L7 segment of spinal cord, the diameter of sensory neurons in the right and left sides were 26.20 and $26.40 \mu \mathrm{m}$ in the weaning group, 30.12 and $30.06 \mu \mathrm{m}$ in the maturation group and 30.05 and $31.49 \mu \mathrm{m}$ in the adult group respectively. The finding show that diameter of sensory neurons was significantly $\quad(\mathrm{P}<0.05) \quad$ increased with advancing age in both L6 and L7 segments of spinal cord (Table, 4).

Table, 4: Number of sensory neurons diameter $(\mu \mathrm{m})$ at level $\mathrm{L} 7$ segment of rabbits spinal cord.

\begin{tabular}{|c|c|c|c|c|}
\hline \multirow{2}{*}{ Side } & \multicolumn{3}{|c|}{$\begin{array}{l}\text { Cell Diameter } \mu \mathrm{m} \\
(\text { Mean } \pm \text { SE })\end{array}$} & \multirow[t]{2}{*}{$P<0.05$} \\
\hline & $\mathbf{W}$ & $\mathbf{M}$ & $\mathbf{A}$ & \\
\hline Right & $26.20 \pm 1.86$ & $30.12 \pm 1.44$ & $30.05 \pm 1.18$ & $*$ \\
\hline Left & $26.40 \pm 1.78$ & $30.06 \pm 1.60$ & $31.49 \pm 1.21$ & $*$ \\
\hline
\end{tabular}

The results of the present study showed a significant decrease in number of sensory neurons of DRG at both L6 and L7 levels of spinal cord with advancing age. While the diameter of sensory neurons were increased significantly with advancing age. This agrees with finding of (20) on sensory neuron in the brain, who observed postnatal changes in neuron cell body diameter and neuron density in newborn, two-week old, and eight-week old golden hamsters. Quantitative data indicated that in both the visual cortex and superior colliculus, neuron cell body diameter increased nearly twofold during the first two-week period following birth and reached maximum size by approximately day 14 . Neuronal density was highest in the newborn and decreased with age in both visual centers. In conclusion, the structures of sensory neurons are altering by the age factors in which morphology, number, and color of neurons, which makes this study applicable one in forensic medicine through it we can know the age of the cadaver.

\section{References}

1. Carrillo, M. and Rodríguez, J. A. (2001). Physiological basis of the reproduction of tropical fish. In: Rodriguez H, Daza P, Carrillo $M$ editors. Fundamentals of inland aquaculture. Bogota (Colombia): National Fisheries Institute INPA. Pp: 205-206.

2. Friedel, R. H.; Schnürch, H.; Stubbusch. J. and Barde, Y. (1997). Identification of genes differentially expressed by nerve growth factor- and neurotrophin-3-dependent sensory neurons. Proc. Natl. Acad. Sci., 94: 12670-12675.

3. Yip, H. K.; Johnson, E. M. and Khan, J. R. (1984). Developing dorsal root ganglion neurons require trophic support from their central processes: Evidence for a role of retrogradely transported nerve growth factor from the central nervous system to the periphery. Proc. Natl. Acad. Sci., USA. 81: 6245-6249.

4. Verdu, E.; Ceballos, D.; Vilches, J. J. and Navarra, X. (2005). Influence of aging on peripheral nerve function and regeneration, $\mathrm{J}$. Periph. Nerv. Syst., 5:191-208.

5. Sturrock, R. R. (1990). Age related changes in neuron number in the mouse red nucleus, $\mathrm{J}$ Hirnforsch. 31(3): 399-403.

6. Morimoto, M. (2009). General physiology of rabbit. In: Houdebine LM, Fan J. Rabbits Biotechnology: Rabbit Genomics, Transgenesis, Cloning and Model. Springer Science and business media, B.V. Pp: 27-33.

7. Mohammad, F. K. (2010). Laboratory Guide in Toxicology: a technical manual for Veterinary Medical and related health Sciences students. $2^{\text {nd }}$ ed. P: 8 .

8. Khan, A. M.; Dilkash, N. A.; Khan, M. A. and Faruqi, N. A. (2009). Morphologically atypical cervical dorsal root ganglion neurons in adult rabbit. Biomedical Res., 20(1):45-49.

9. Jackson, M.; Ganel, R. and Rothstein, J. D. (2002). Model of Amylotrophic Sclerosis. Curent Protocol in Neuroscience No1. 
10. Banecroft, J. and Stevens, A. (1982). Theory and practice of histological techniques. $2^{\text {nd }}$ ed. Pp: 194-198.

11. Abdul-Jabbar, H. M. and Naqvi, A. (2007). Motor and sensory neurons of the rat. A Horseradish peroxidase study. Professional Med. J., 14(2): 328-336.

12. Mertens, A. H.; Nagler, J. M.; Galdermans, D.; Slabbynck, H. R.; Weise, B. and Coolen, D. (1998). Quality assessment of protected specimen brush samples by microscopic cell count. Am. J. Respir Crit Care Med., 157(4 Pt 1): 1240-1243.

13. Terao, S.; Sobue, G.; Hashizume, Y.; Li, M.; Inagaki, T. and Mitsuma, T.(1996). Age related changes in human spinal ventral horn cells with special reference to loss of small neurons in the intermediate zone: a quantitative analysis. Acta Neuropathol. 92(2):14-109.

14. Cary, N. C. (2001). SAS, Institute. SAS U Version 6th ed. SAS Institute Inc.

15. Bowen, R. L. and Atwood, C. S. (2004). Living and Dying for Sex. Gerontology. 50(5): 265-290.
16. An, M.; Rushu, L. and Henion, P. D. (2002). Differentiation and maduration of Zebra fish dorsal root and sympathetic ganglion neurons. J. Comp. Neurol., 446: 267-275

17. Berg, J. S. and Farel, P. B. (2000). Developmental regulation of sensory neuron number and limb innervation in the mouse. Develop. Brain Res., 125: 21-30.

18. Jaramillo, J.; Gómez-Ramírez, E.; Caldas, M.L.; Rodríguez, D. and Hurtado, H. (2009). Histology and morphometry of dorsal root ganglia and their neurons in a fish of indeterminate growth the White Cachama (Piaractus brachypomus), Current Biol., 31(90): 43-52.

19. Martínez, M.; Quiroga, N.Y.; Castellanos, J. E. and Howard, H. (2000). Neural subpopulations present in the dorsal root ganglion. Biomedicine, 20: 248-260.

20. Ptacek, J. M. and Dubin, L. F. (1974). Developmental changes in neuron size and density in the visual cortex and superior colliculus of the postnatal golden hamster. J., Comp Neurol. 158(3): 237-242.

$$
\begin{aligned}
& \text { مقارنة التخير ات النسبية في العصبونات الحسية لعقدة الجذر الظهري للعصب الشوكي في فئات عمرية }
\end{aligned}
$$

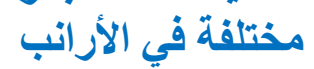

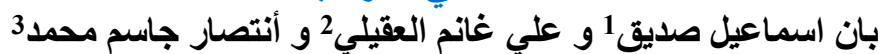

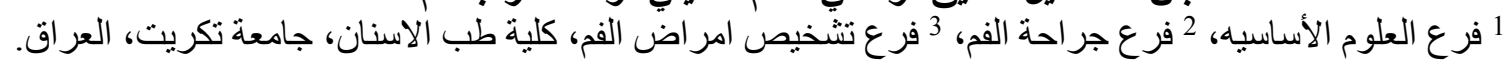

$$
\begin{aligned}
& \text { E-mail: ali.okaili@gmail.com } \\
& \text { الخلاصة فردة }
\end{aligned}
$$

هدفت الدراسة إلى مقارنة التغيرات النسجية التي تحدث في العصبونات الحسية الموجودة في العقد الحسية للجذر الظهري

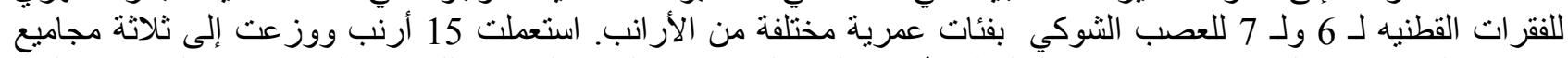

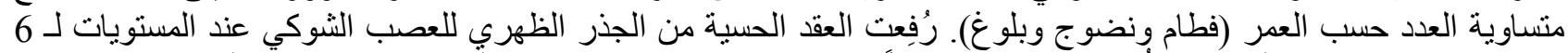

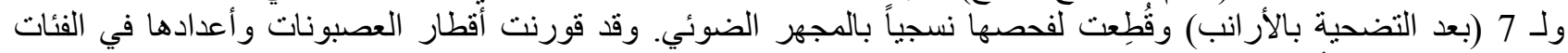

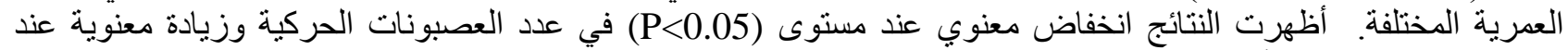
مستوى (P<0.05) في أقطار ها مع تقدم العمر. نستنتج من هذه الدراسة إن تركيب العصبونات الحسية تتغير بتقدم العمر و التي

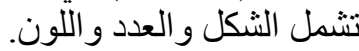
الكلمات المفتاحيه: العصبونات الحسيه، العقد الحسيه والعقد العصبيه للجذر الظهري، العصب الظهري، الاراتب. 